\title{
An Econometric Time Series GDP Model Analysis: Statistical Evidences and Investigations
}

\author{
Habib Ahmed Elsayir \\ Department of Mathematics, Al Qunfudha University College, Umm Al Qura University, Al Qunfudha, Saudi Arabia \\ Email: Habibsayiroi@Yahoo.com
}

How to cite this paper: Elsayir, H.A. (2018) An Econometric Time Series GDP Model Analysis: Statistical Evidences and Investigations. Journal of Applied Mathematics and Physics, 6, 2635-2649. https://doi.org/10.4236/jamp.2018.612219

Received: November 4, 2018

Accepted: December 24, 2018

Published: December 27, 2018

Copyright $\odot 2018$ by author and Scientific Research Publishing Inc. This work is licensed under the Creative Commons Attribution International License (CC BY 4.0).

http://creativecommons.org/licenses/by/4.0/

\section{(c) (i) Open Access}

\begin{abstract}
This article aims to provide an analysis for a time series data of gross domestic product (GDP) of the Sudan. An econometric time series model with macroeconomic variables is conducted. Since a non-stationary time series must be made stationary, some statistical tests are followed so that the time series become stationary series. After applying these tests, the time series became stationary and integrated of order I. Box-Jenkins procedure is used to determine ARMA. OLS is used to estimate the models parameters. Performances chosen ARIMA model are verified on the basis of classical statistical tests and forecasting. The model features are interpreted on the basis of standard measures of forecasting performance.
\end{abstract}

\section{Keywords}

ARIMA Model, GDP, Box-Jenkins Models, Stationary Time Series

\section{Introduction}

As a measure of performance for an economy, the (GDP), gross domestic product, is the value of all final goods and services produced within a country in a year. GDP data is widely used economic data in the field of time series modeling and analysis. GDP data are used to meet a wide variety of requirements, such as in industry, finance, research institutions, and other fields. Forecasting economic model is an essential component of a country's economy decision-making process. The GDP forecast is necessary for policy makers to forecast economic model. For these reasons, this paper investigates the performance of GDP model for the Sudan. It aims at analyzing time series econometric model of macroeconomic variable GDP in the country. 
Time series models and analysis has been discussed in [1] [2] [3] [4] [5] and many others. Time series analysis aims at identifying data patterns and trends as well as explanation of data modeling and forecasting. Two principal approaches are adopted to maintain time series analysis which depends on the time or the frequency domain. Several procedures are used to analyze data within these domains. A useful common technique is the Box-Jenkins ARIMA method [1], which can be used for univariate or multivariate data set analyses. The ARIMA technique uses moving averages (MA), smoothing, and regression methods to detect and remove data autocorrelation. Tools of time series analysis have been intensively discussed by [6].

Many statistical tests are used in time series models in order to make it a stationary series and integrated; thus, Box-Jenkins procedure is used for the determination of ARMA, and OLS method is used to estimate the model parameters. In the following sections, among the techniques those are useful for analyzing will be identified.

This paper is organized as follows: Chapter 2 is devoted to the proposed model of the study. A background about data collection and methodology is presented in Chapter 3 while Chapter 4 is devoted to data analysis and results which has been discussed in Chapter 5 and then a brief conclusion has been introduced in Chapter 6.

\section{The Proposed Model}

The methodology of time series analysis composed of two steps: constructing a data model for that time series, and forecasting the future values.

For a regular time series pattern, the value of the series, $Y_{t}$, should be a function of previous values. If $Y$ is the target value that we are trying to model and predict, and $Y_{t}$ is the value of $Y$ at time $t$, then the goal is to build a model of the type:

$$
Y_{t}=f\left(Y_{t-1}, Y_{t-2}, Y_{t-3}, \ldots, Y_{t-n}\right)+e t
$$

where $Y_{t-1}$ is the previous observation value of $Y, Y_{t-2}$ is the value two observations ago, etc., and $e_{t}$ (a random shock), represents noise that does not follow a predictable pattern. Variables Values occurring prior to the current observation are called lag values. In a repeating pattern time series, the value of $Y_{t}$ is usually highly correlated with $Y_{t-c y c l e}$. Thus, the goal of constructing a time series model is to build a model such that the error between the predicted value of the target variable and the actual value is as small as possible.

Consider a time series of data $X_{t}$ the ARMA model consists of two parts, an autoregressive (AR) part and a moving average (MA) part. Following [7], the $\operatorname{AR}(p)$ model is written in the form:

$$
Y_{t}=c+\sum_{i=1}^{p} \varphi_{i} Y_{t-i}+\varepsilon_{t}
$$

where $\varphi_{i}, \ldots, \varphi_{p}$ are the model parameters, $c$ is a constant (which may be omit- 
ted for simplicity) and $\varepsilon_{t}$ is an error term. The MA $(q)$ notation stands for the moving average model of order $q$ :

$$
Y_{t}=\varepsilon_{t}+\sum_{i=1}^{q} \theta_{i} \varepsilon_{t-i}
$$

where the $\theta_{1}, \ldots, \theta_{q}$ are the parameters of the model and the $\varepsilon_{\mathrm{t}}, \mathcal{E}_{\mathrm{t}-1}, \ldots$ are, the error terms.

The notation ARMA $(p, q)$ refers to the model with $p$ autoregressive terms and $q$ moving average terms. This model contains the $\operatorname{AR}(p)$ and MA $(q)$ models,

$$
Y_{t}=\varepsilon_{t}+\sum_{i=1}^{p} \varphi_{i} Y_{t-i}+\sum_{i=1}^{q} \theta_{i} \varepsilon_{t-i}
$$

where the error terms $\varepsilon_{\mathrm{t}}$ are assumed to be independent identically-distributed random variables with mean zero and $\varepsilon_{\mathrm{t}}-\mathrm{N}\left(0, \sigma^{2}\right)$ where $\sigma^{2}$ is the variance.

The process $(Y)$ is said to be $\operatorname{ARIMA}(p, d, q)$ if:

$$
(1-l)^{d} \varnothing^{*}(l) Y_{t}=c+\theta(l) \varepsilon_{t}
$$

where

$$
\varnothing^{*}(l) \text { is defined in } \varnothing(l)=(1-l) \varnothing^{*}(l),
$$

$\varnothing^{*}(z) \neq 0$ for all $|z| \leq 1$. And $\theta(l)$ is defined in $\theta(z) \neq 0$ for all $|z| \leq 1$.

The process $(Y)_{t}$ is stationary if and only if $d=0$ in which case it reduces to $\operatorname{ARMA}(p, q)$ process:

$$
\varnothing(l) Y_{t}=c+\theta(l) \varepsilon_{t}
$$

The Box-Jenkins methodology [1] is a five-step technique for identifying, selecting, and assessing models for a type of time series data. These steps are:

1) Time series stationary. A time series is said to be stationary if both its mean and its variance remain constant through time. Classical Box-Jenkins ARMA models only work satisfactorily with stationary time series.

2) Identify a (stationary) conditional mean model for underlying data. The sample autocorrelation functions (ACF) and partial autocorrelation functions (PACF) can help with this selection. For an autoregressive (AR) process, the sample ACF decays gradually, but the sample PACF cuts off after a few lags. Conversely, for a moving average process (MA), the sample ACF cuts off after a few lags, but the sample PACF decays gradually. If both the ACF and PACF decay gradually, consider an Auto-Regressive Moving Average (ARMA) model.

3) Model Specification stage, and estimation of the parameters required.

4) Model checks for goodness-of-fit by using methods such as Proportion of variance explained by model or Correlation between actual and predicted. Residuals should be uncorrelated, homoscedastic, and normally distributed with constant mean and variance.

5) Forecasting: The model can be used to forecast or generate simulations over a period of time after checking its goodness of fit and its forecasting ability. 
Adopting the ARIMA (auto-regressive, integrated, moving average) method iteratively, to best-fit time series data, then auto-regressive component (AR) in ARIMA is designated as $p$, the integrated component (I) as $d$, and moving average (MA) as $q$. The AR component represents the effects of previous data observations. The I component represents trends, including seasonality. And the MA component represents effects of previous random shocks (or error). To fit an ARIMA model to a time series, the order of each model component must be selected. Usually a small integer value (usually 0,1 , or 2 ) is determined for each component.

\section{Data and Methodology of Collection}

The GDP is equals to the total expenditures for all final goods and services produced within the country in a stipulated period of time. It is the sum of gross value added by all resident producers in the economy plus any product taxes and minus any subsidies not included in the value of the products [8].

The Sudan Central Bureau of Statistics (CBS) issues annual report includes all National accounts, while the Central Bank of the Sudan [9] also issues its annual economic records. Annual collections of the official national accounts data reported to the United Nations Statistics Division by the countries in form of the United Nations [8]. If a full set of official data is not reported, estimation procedures are employed to obtain estimates for the entire time series.

Annual percentage growth rate of GDP at market prices is based on constant local currency. Aggregates are based on constant U.S. dollars. Reported by the World Bank, the GDP in Sudan was worth 97.156 billion US dollars in 2015. It represents 0.14 percent of the world economy. GDP in Sudan averaged 18.774 USD Billion from 1960 until 2015, reaching an all time high of 97.156 USD Billion in 2015 and a record low of 1.307 USD Billion in 1960.

According to [10], Sudan's real GDP is predicted to recede slightly that year to $2.7 \%$ because of fiscal consolidation and is projected to reach $3.8 \%$ in 2015 . However, according to the African Economic Outlook (AEO) report, the country's real GDP grew in 2014 by $3.6 \%$ up from $1.4 \%$ in 2012 due to increase of agriculture, oil, gold and transit revenues. In 2005, agricultural sector reported contribution of $33.2 \%$ to GDP, industry about $22 \%$, and $44.8 \%$ for services sector while in 2014, Agricultural sector contributed to the GDP by about $27.5 \%$, industry around $20.7 \%$ and the services sector $51.8 \%$ for the year after. The reports also stated that inflation remained high at $36.5 \%$ and raised to $36.9 \%$ in 2014 and drop to $16.9 \%$ for 2015 . The trade balance has been reported negative since 1985 except for the year 2000 [9].

The resulting high external and internal deficits, coupled with the sustained American sanctions as well as the security concerns in the country, affected the economic situation which led to devaluation to supplement the budget, including the devaluation of the currency by $29 \%$ and removal of fuel subsidies worth SDG 3.6 billion (Sudanese pounds) about 1.2\% of GDP, resulting in riots. Eco- 
nomic linkages and value addition were weakened during the period of oil-driven growth (1999-2011), mainly in agriculture (which provided $47.6 \%$ of total jobs in 2011). The major field of government expenditure might be on the security services, though no official figures were displayed.

Also, the high taxes along the supply chains and the recent increase in tariffs on imported inputs in addition to the high costs of energy and infrastructure services raised domestic resource costs and reduced domestic value addition. During 2001-2007, 41\% of all factories closed because of intense competition.

After the production of oil fields in the southern Sudan from 1998 onward, the economy developed rapidly, reaching levels of $8 \%$ per annum. However, the fall in oil revenues after the secession of what is now South Sudan in 2011 has affected greatly on GDP growth, which stands negative (-6\%) in 2013.

GDP per capita-current prices estimated as US $\$ 1985$ for 2014 while the GDP (Purchasing Power Parity) is estimated to be 168 billion of International dollars in 2015, while the estimate of GDP per capita-PPP is 4522 International Dollars for 2014, (see [9] and [8]).

Sudan's trade suffers from several difficulties, despite persistent efforts by the government to liberalize trade. Import restrictions, discriminatory taxes, delays in customs clearance and non-transparent regulations are some of the factors impeding Sudanese trade.

Some chief import commodities of Sudan are: Manufactured goods, Transport equipment, Medicines and Chemicals. The main share of Sudan's export partners in its total trade, according to CIA World Fact book reports for 2009, UAE (32\%), China (16\%), Saudi Arabia (15.5\%), while the import partners are China (26.3\%), UAE (10\%), India (9\%), Egypt (5.6\%) and Turkey (4.7\%).

\section{Data Analysis}

Time series are analyzed in order to understand the nature of underlying structure and mechanism of the function that produce the observations. In this section, the data of GDP statistics of Sudan, which include the current and constant prices in million US\$ for the period (1960-2015) will be investigated.

Figures 1-3 show a line graph of GDP levels in the period under consideration. Overall, the line graph shows a clear dominance of a long-term upward trend, suggesting a non-stationary time series in levels. In this analysis of GDP data, a summary of the model descriptive statistics for GDP) is given in Table 1, where one way ANOVA Summary for the same model is shown in Table 2 and Table 3 for the classical regression model summarized in Table 4, and the coefficients are presented in Table 5 with summary and parameter estimates using linear equation method are shown in Table 6. Significant tests are also summarized for the model. Using Time Series Modeler, the model type was shown in the estimates are based on $5 \%$ level of significance. The R-square value is over $61 \%$ for linear, logarithmic, quadratic and exponential methods, and the F value of regression is highly significant in Table 7 and Figure 4. Then the model 


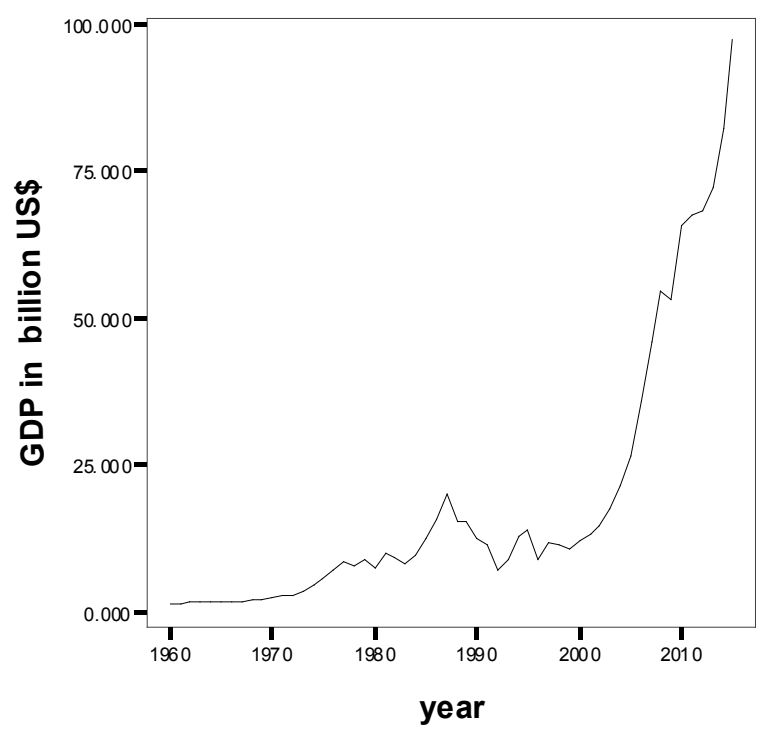

Dot/Lines show Means

Figure 1. GDP 1960-2015 in billion US\$. Source: world Bank.

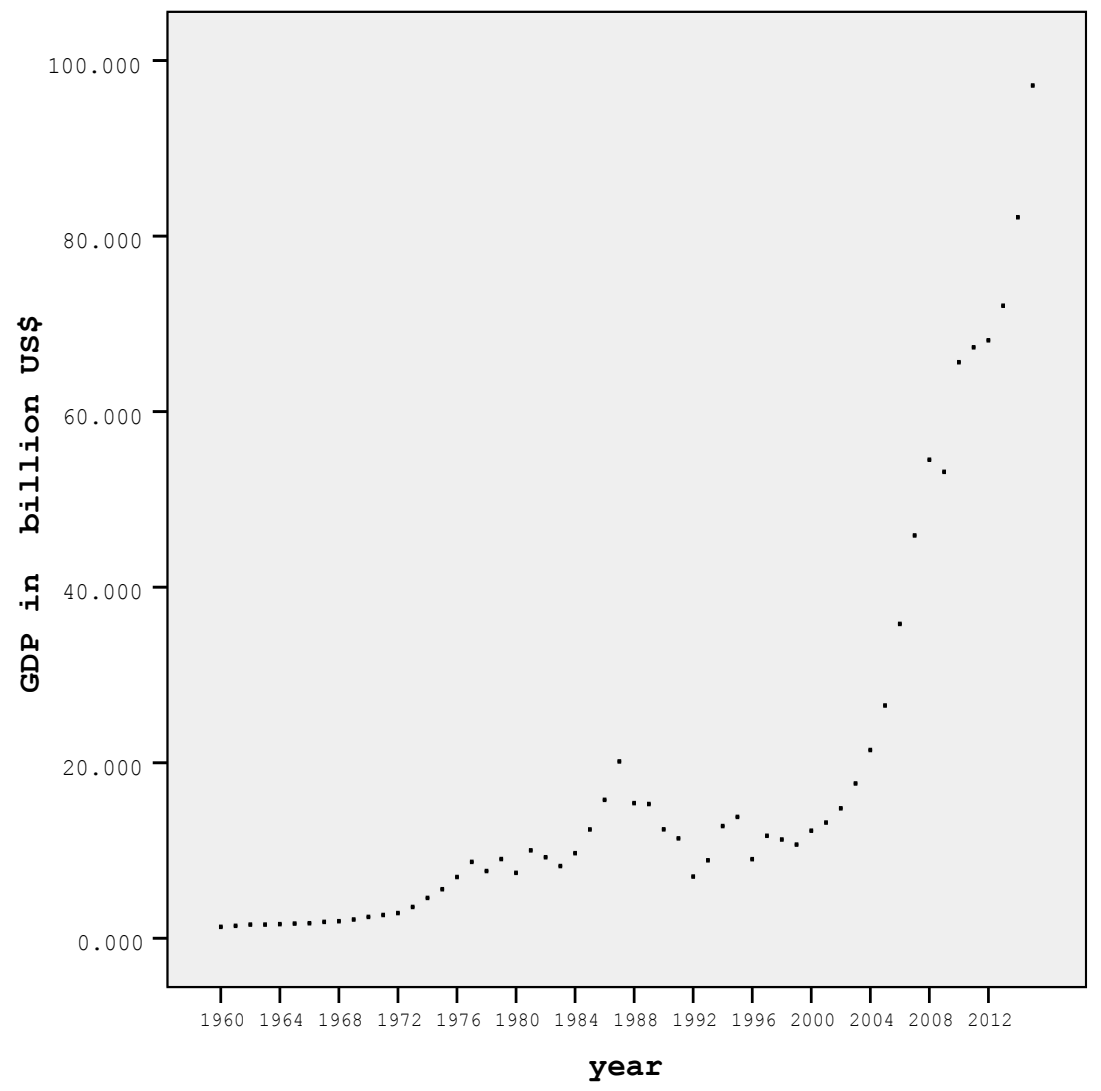

Figure 2. Data Explore Chart Sudan GDP in billion US\$ (1960-2015).

Table 1. Descriptive statistics.

\begin{tabular}{cccccc}
\hline Std. Deviation & Mean & Maximum & Minimum & $\mathrm{N}$ & \\
\hline 23.207303 & 18.77350 & 97.156 & 1.307 & 56 & GDP in billion US\$ \\
& & & & 56 & Valid N (listwise) \\
\hline
\end{tabular}




\section{GDP in billion US\$}

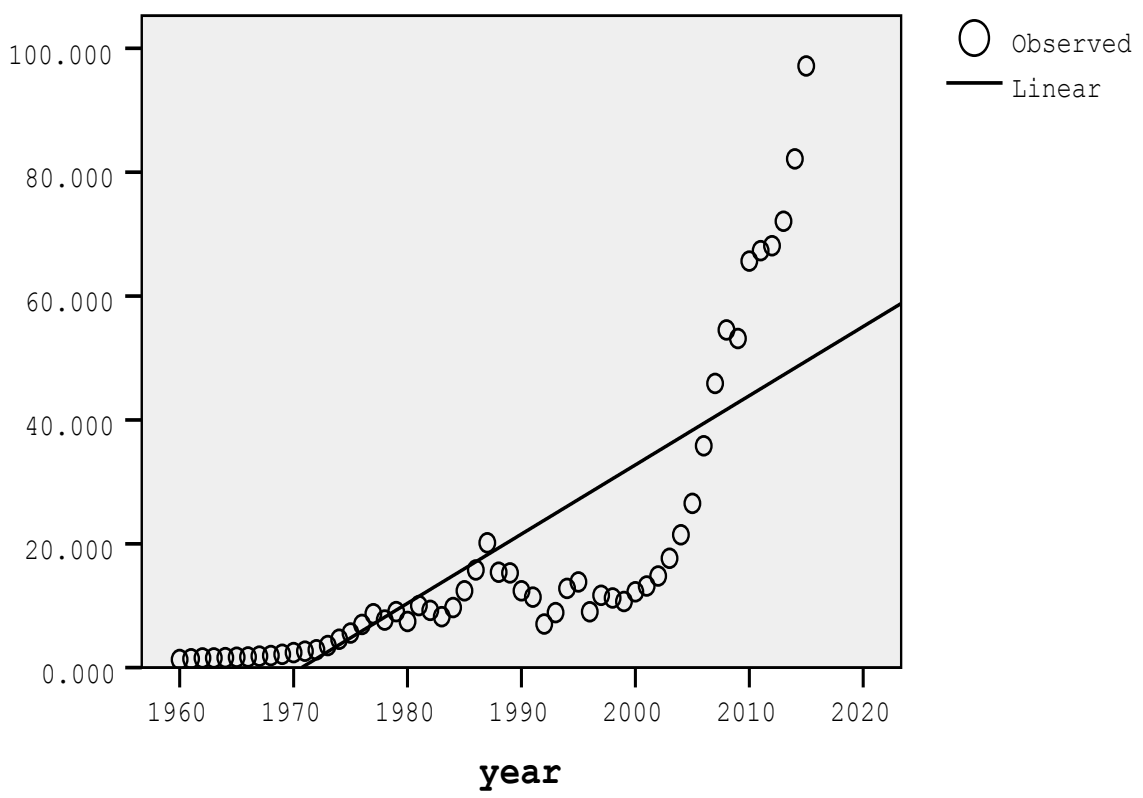

Figure 3. Linear GDP model.

GDP in billion US\$

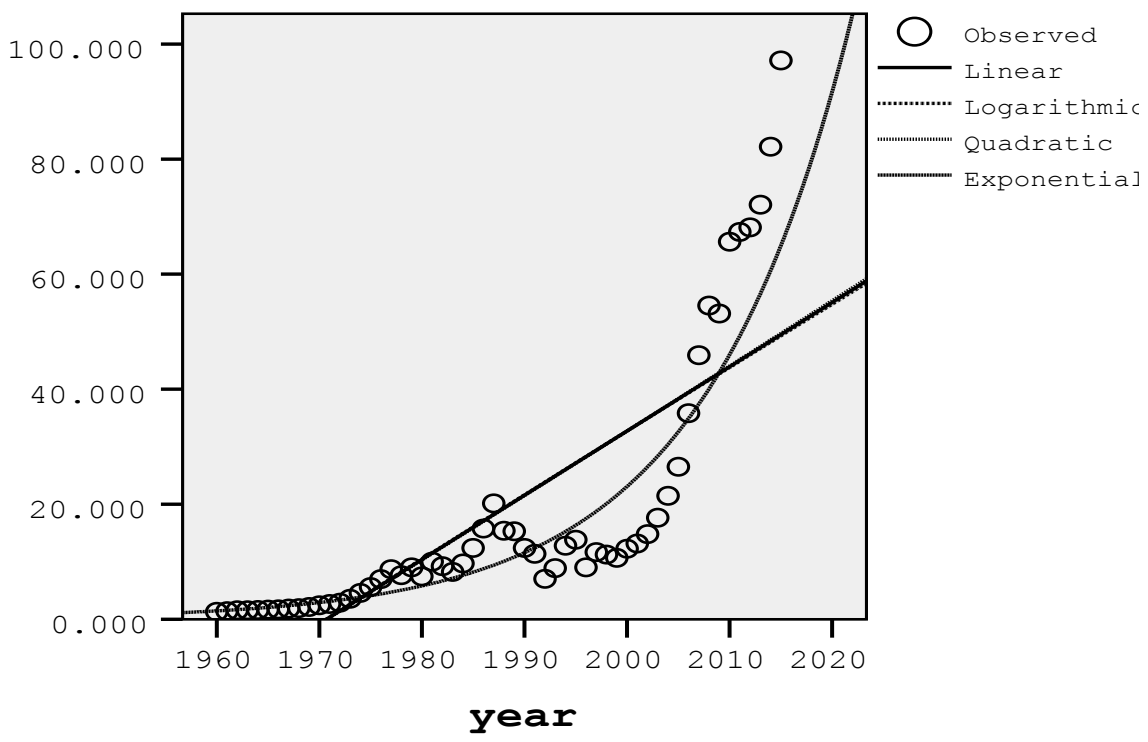

Figure 4. Selected GDP models.

Table 2. One-way ANOVA for GDP.

\begin{tabular}{|c|c|c|c|c|c|}
\hline \multirow[t]{4}{*}{ Sig. } & $\mathrm{F}$ & Mean Square & $\mathrm{df}$ & Sum of Squares & \\
\hline & & 538.579 & 55 & 29621.840 & Between Groups \\
\hline & & & 0 & 0.000 & Within Groups \\
\hline & & & 55 & 29621.840 & Total \\
\hline
\end{tabular}

GDP in billion US\$. 
Table 3. ANOVA.

\begin{tabular}{ccccccc}
\hline \multicolumn{7}{c}{ ANOVA (b) } \\
\hline Sig. & F & Mean Square & df & Sum of Squares & & Model \\
\hline 0.000 (a) & 86.756 & 18257.653 & 1 & 18257.653 & Regression & \\
& & 210.448 & 54 & 11364.187 & Residual & 1 \\
& & 55 & 29621.840 & Total & \\
\hline
\end{tabular}

(a) Predictors: (Constant), year; (b) Dependent Variable: GDP in billion US\$.

Table 4. Classical regression model summary.

\begin{tabular}{ccccc}
\hline Std. Error of the Estimate & Adjusted R Square & R Square & R & Model \\
\hline 14.506822 & 0.609 & 0.616 & $0.785(\mathrm{a})$ & 1 \\
\hline
\end{tabular}

(a) Predictors: (Constant), year.

Table 5. Model coefficients.

\begin{tabular}{|c|c|c|c|c|c|c|}
\hline \multicolumn{7}{|c|}{ Coefficients (a) } \\
\hline \multirow{2}{*}{$\begin{array}{c}\text { Sig. } \\
\text { Std. Error }\end{array}$} & \multirow[b]{2}{*}{ B } & \multirow{2}{*}{$\begin{array}{c}\text { Standardized } \\
\text { Coefficients } \\
\text { Beta }\end{array}$} & \multicolumn{2}{|c|}{$\begin{array}{l}\text { Unstandardized } \\
\text { Coefficients }\end{array}$} & & \multirow{2}{*}{ Model } \\
\hline & & & Std. Error & B & & \\
\hline 0.000 & -9.235 & & 238.381 & -2201.505 & (Constant) & \\
\hline 0.000 & 9.314 & 0.785 & 0.120 & 1.117 & year & 1 \\
\hline
\end{tabular}

(a) Dependent Variable: GDP in billion US\$.

Table 6. Model summary and parameter estimates.

\begin{tabular}{cccccccc}
\hline \multicolumn{2}{c}{ Parameter Estimates } & \multicolumn{5}{c}{ Model Summary } & Equation \\
\hline b1 & Constant & Sig. & df2 & df1 & F & R Square & Linear \\
1.117 & -2201.505 & 0.000 & 54 & 1 & 86.756 & 0.616 & L \\
\hline
\end{tabular}

Dependent Variable: GDP in billion US\$. The independent variable is year.

Table 7. Model summary and parameter estimates.

\begin{tabular}{ccccccccc}
\hline \multicolumn{3}{c}{ Parameter Estimates } & \multicolumn{9}{c}{ Model Summary } & \multirow{2}{*}{ Equation } \\
\cline { 1 - 6 } b2 & b1 & Constant & Sig. & df2 & df1 & F & R Square & \\
\hline & 1.117 & -2201.505 & 0.000 & 54 & 1 & 86.756 & 0.616 & Linear \\
& 2215.325 & -16805.735 & 0.000 & 54 & 1 & 85.776 & 0.614 & Logarithmic \\
0.000 & 0.000 & -1093.851 & 0.000 & 54 & 1 & 87.750 & 0.619 & Quadratic \\
& 0.069 & $2.84 \mathrm{E}-059$ & 0.000 & 54 & 1 & 472.242 & 0.897 & Exponential \\
\hline
\end{tabular}

Dependent Variable: GDP in billion US\$. The independent variable is year.

described in Table 8 has been reached (ARIMA $(0,0,0)$, and its fit shown in Table 9. The model statistics has been shown in Table 10 accompanied by descriptive graph (Figure 5), which suggested upward trend for the series.

When building a time series model, it is necessary to include lag values that 
Table 8. Model description.

\begin{tabular}{cccc}
\hline Model Type & & & \\
\hline ARIMA $(0,0,0)$ & Model_1 & GDP in billion US\$ & Model ID \\
\hline
\end{tabular}

Table 9. Model fit.

\begin{tabular}{|c|c|c|c|c|c|}
\hline Fit statistic & Mean & SE & Minimum & Maximum & $\begin{array}{c}\text { Percentiles } \\
5,10,25,50,75,90,95\end{array}$ \\
\hline $\begin{array}{l}\text { Stationary } \\
\text { R-squared }\end{array}$ & 0.616 & & 0.616 & 0.616 & 0.616 \\
\hline R-squared & 0.616 & & 0.616 & 0.616 & 0.616 \\
\hline RMSE & 14.507 & & 14.507 & 14.507 & 14.507 \\
\hline MAPE & 154.318 & & 154.318 & 154.318 & 154.318 \\
\hline MaxAPE & 1014.104 & & 1014.104 & 1014.104 & 1014.104 \\
\hline MAE & 10.755 & & 10.755 & 10.755 & 10.755 \\
\hline MaxAE & 47.662 & & 47.662 & 47.662 & 47.662 \\
\hline
\end{tabular}

Table 10. Model statistics.

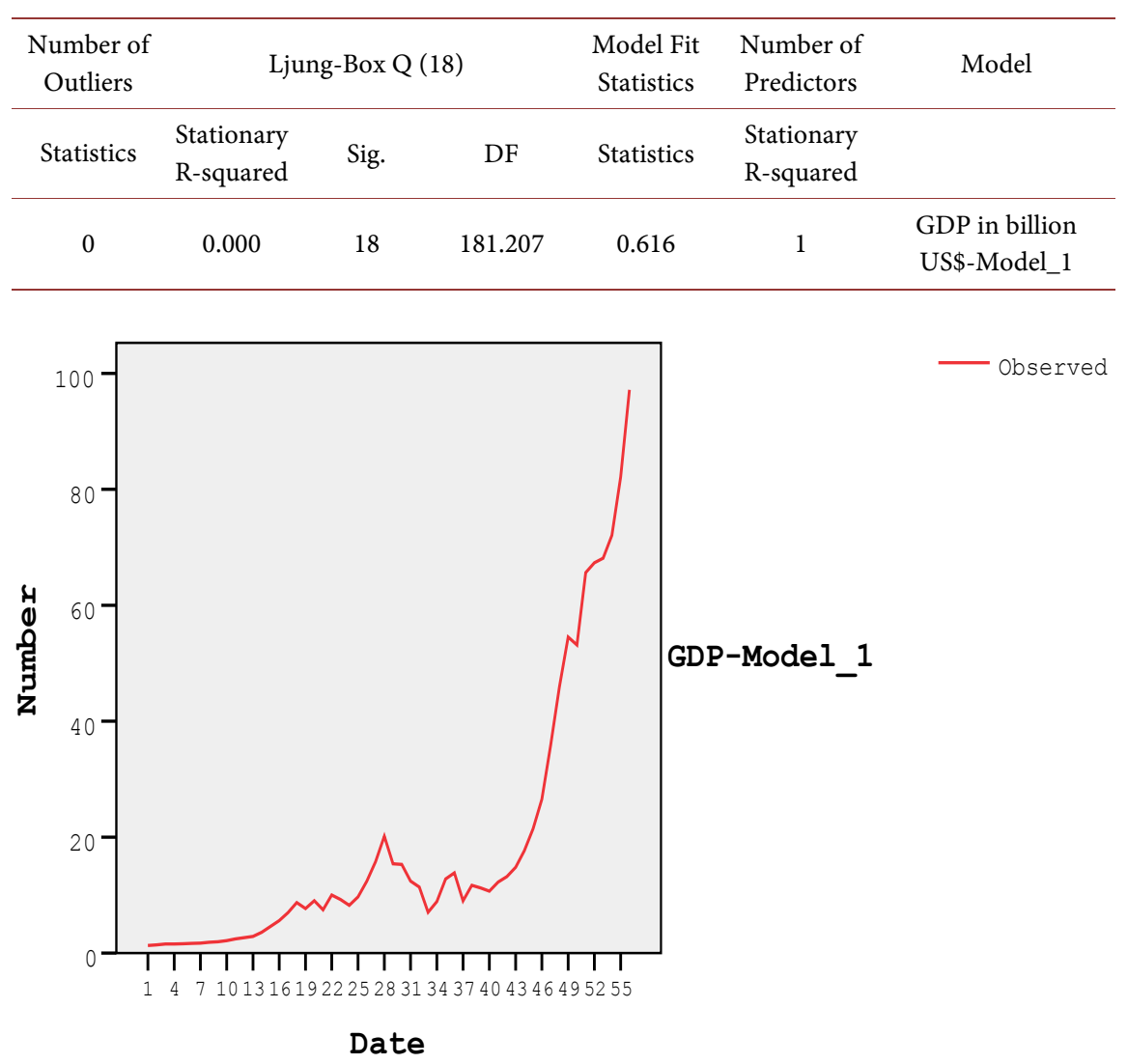

Figure 5. GDP model.

have large, positive autocorrelation values or that have large negative autocorrelations. The partial autocorrelation is the autocorrelation of time series observations separated by a lag of $k$ time units with the effects of the intervening obser- 
vations eliminated. Autocorrelation and partial autocorrelation tables are also provided for the residuals (errors) between the actual and predicted values of the time series. Proportion of variance explained by model is the best single measure of how well the predicted values match the original values. If the predicted values exactly match the original values, then the model would explain $100 \%$ of the variance. In fact this is not always the case (here the model explains $61.6 \%$ of the variance due to the R square value), as seen in Table 3, Table 6 and Table 7.

Examining the autocorrelation table shown in Table 11, we see that the highest autocorrelation is -0.313 which occurs with a lag of 15 . Hence we want to be sure to include lag values up to 15 when building the model.

The autocorrelation ACF (Table 11 and Figure 6) and partial autocorrelation PACF tables (Table 12 and Figure 7) provide valuable information about the significance of the lag variables. An autocorrelation is the correlation between the target variable (GDP) and lag values for the same variable. Correlation values range from -1 to +1 . A value of +1 indicates that the two variables move together perfectly; a value of -1 indicates that they move in opposite directions (see the results of Table 12. The second column of the autocorrelation table shows the standard error of the autocorrelation, this is followed by the t-statistic in the third column. The right side of the autocorrelation table is a bar chart with asterisks used to indicate positive or negative correlations right or left of the centerline. The dots shown in the chart mark the points two standard deviations from zero. If the autocorrelation bar is longer than the dot marker (that is, it covers it), then the autocorrelation should be considered significant. In this model, significant autocorrelations occurred for all lags except for lag 15. Based on the assumption that the series are not cross correlated and that one of the series is white noise, the cross correlations and range of lags (from -7 to +7 are displayed in Table 13 and Figure 8). The figure shows confidence limit to be all above zero for the GDP.

GDP in billion US\$

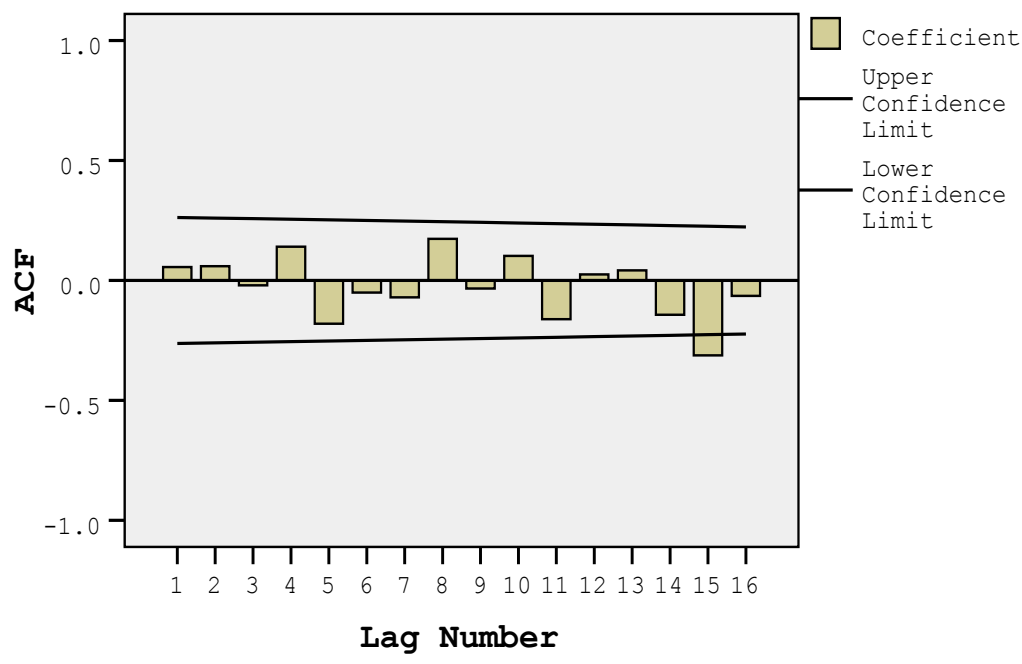

Figure 6. Autocorrelation function. 


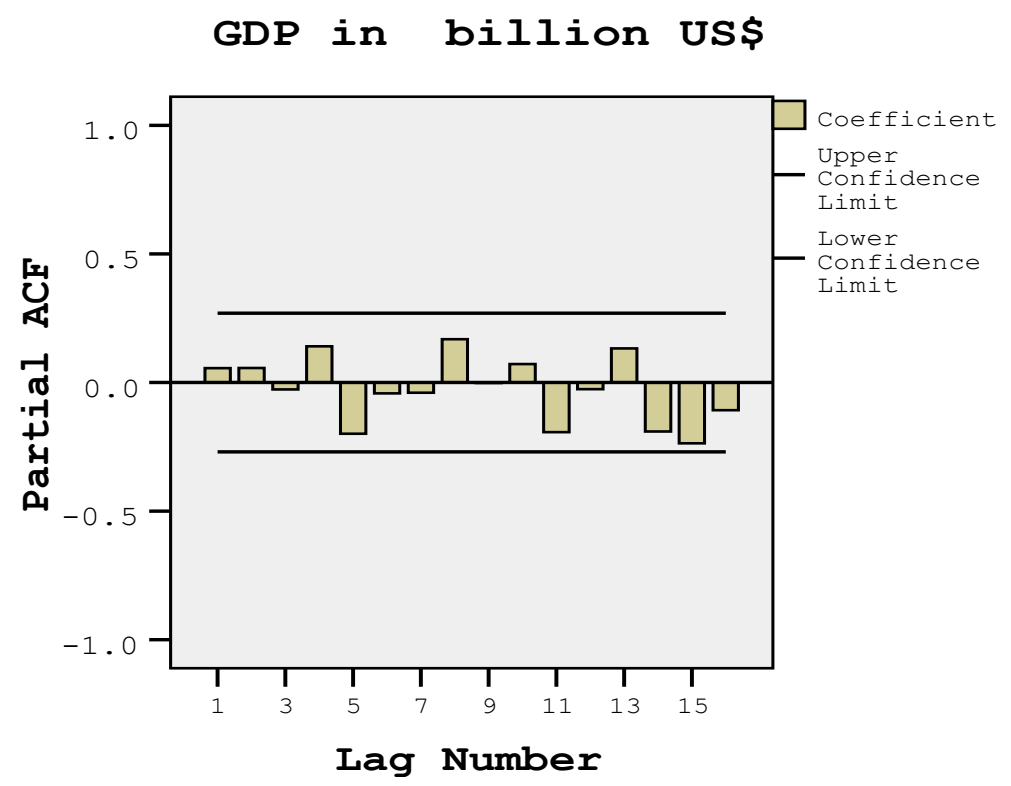

Figure 7. Partial autocorrelation function.

\section{GDP in billion US\$ with year}

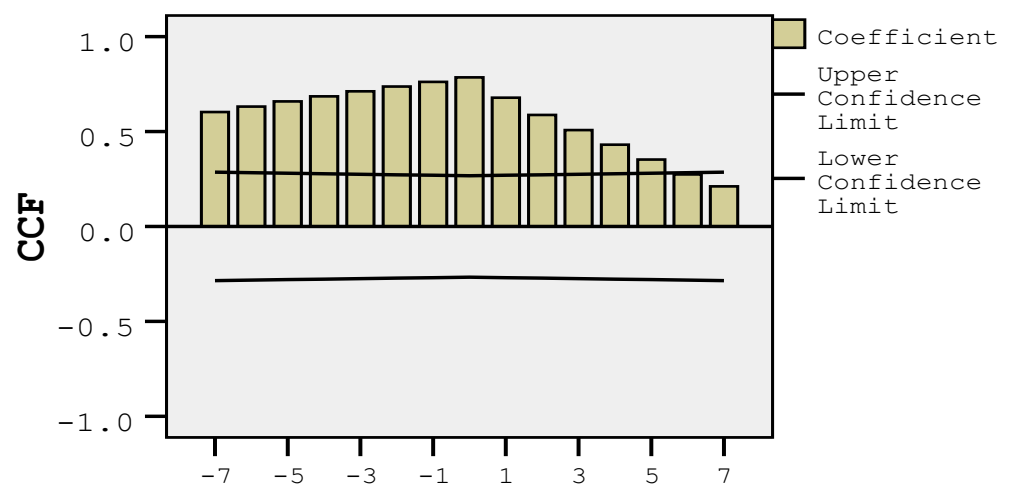

Lag Number

Figure 8. CCF.

Table 11. Autocorrelations for GDP in billion US\$.

\begin{tabular}{cccccc}
\hline & Box-Ljung Statistic & & Std. Error (a) & Autocorrelation & \multirow{2}{*}{ Lag } \\
\cline { 1 - 4 } $\mathrm{df}$ & Value & Sig. (b) & $\mathrm{df}$ & Value & \\
\hline 0.670 & 1 & 0.182 & 0.131 & 0.056 & 1 \\
0.822 & 2 & 0.392 & 0.130 & 0.060 & 2 \\
0.937 & 3 & 0.416 & 0.129 & -0.020 & 3 \\
0.803 & 4 & 1.630 & 0.128 & 0.141 & 4 \\
0.597 & 5 & 3.675 & 0.126 & -0.181 & 5 \\
0.699 & 6 & 3.839 & 0.125 & -0.050 & 6 \\
0.761 & 7 & 4.162 & 0.124 & -0.070 & 7 \\
0.628 & 8 & 6.173 & 0.122 & 0.174 & 8 \\
\hline
\end{tabular}




\section{Continued}

\begin{tabular}{llllll}
\hline 0.715 & 9 & 6.250 & 0.121 & -0.034 & 9 \\
0.728 & 10 & 6.978 & 0.120 & 0.102 & 10 \\
0.637 & 11 & 8.833 & 0.118 & -0.161 & 11 \\
0.713 & 12 & 8.880 & 0.117 & 0.025 & 12 \\
0.772 & 13 & 9.012 & 0.116 & 0.042 & 13 \\
0.719 & 14 & 10.574 & 0.114 & -0.143 & 14 \\
0.251 & 15 & 18.229 & 0.113 & -0.313 & 15 \\
0.292 & 16 & 18.561 & 0.112 & -0.064 & 16 \\
\hline
\end{tabular}

Series: GDP in billion US\$. (a) The underlying process assumed is independence (white noise); (b) Based on the asymptotic chi-square approximation.

Table 12. Partial autocorrelations.

\begin{tabular}{|c|c|c|}
\hline Std. Error & Partial Autocorrelation & Lag \\
\hline 0.135 & 0.056 & 1 \\
\hline 0.135 & 0.057 & 2 \\
\hline 0.135 & -0.027 & 3 \\
\hline 0.135 & 0.141 & 4 \\
\hline 0.135 & -0.199 & 5 \\
\hline 0.135 & -0.042 & 6 \\
\hline 0.135 & -0.039 & 7 \\
\hline 0.135 & 0.168 & 8 \\
\hline 0.135 & -0.002 & 9 \\
\hline 0.135 & 0.072 & 10 \\
\hline 0.135 & -0.193 & 11 \\
\hline 0.135 & -0.026 & 12 \\
\hline 0.135 & 0.133 & 13 \\
\hline 0.135 & -0.191 & 14 \\
\hline 0.135 & -0.236 & 15 \\
\hline 0.135 & -0.108 & 16 \\
\hline
\end{tabular}

Series: GDP in billion US\$.

Table 13. Cross correlations, range of lags from -7 to 7 .

\begin{tabular}{ccc}
\hline Std. Error (a) & Cross Correlation & Lag \\
\hline 0.143 & 0.603 & -7 \\
0.141 & 0.631 & -6 \\
0.140 & 0.658 & -5 \\
0.139 & 0.685 & -4 \\
0.137 & 0.711 & -3
\end{tabular}




\section{Continued}

\begin{tabular}{llc}
\hline 0.136 & 0.737 & -2 \\
0.135 & 0.761 & -1 \\
0.134 & 0.785 & 0 \\
0.135 & 0.678 & 1 \\
0.136 & 0.587 & 2 \\
0.137 & 0.507 & 3 \\
0.139 & 0.431 & 4 \\
0.140 & 0.352 & 5 \\
0.141 & 0.274 & 6 \\
0.143 & 0.211 & 7
\end{tabular}

Series Pair: GDP in billion US\$ with year. (a) Based on the assumption that the series are not cross correlated and that one of the series is white noise.

Thus, if we rely on this information, we may conclude that we have a good fit. From Table 5, we could put the model as the following form:

$$
y=\beta_{0}+\beta_{1} x_{i} \text {, or GDP }=9.314+0.785 x_{i} \text {, with standard error }(0.120) \text { for } \beta_{1}
$$

Based on forecasting model results, the forecasted values for Sudan GDP (in in billion US\$), are 99.51 (for the year 2017), 101 (2018), 106.58 (2019) and 112.62 (for the year 2020). The Annual growth rates are estimated to be about 5.3\%, $5.36 \%, 5.52 \%$ and $5.67 \%$ for the above years respectively.

\section{Discussion}

We evaluate Autoregressive Integrated Moving Average (ARIMA) model of the GDP series using Box-Jenkins methodology by using four different equations which are, linear, logarithmic, quadratic and exponential equations. I also successively eliminated the AR or the MA term while leaving the other term in, but still got higher values for all test parameters. Based on the parameter values, I found that the ARIMA $(0,0,0)$ is the best model for the data. Comparing with other models, ARIMA model has been selected as the final model. We provide method for prediction and forecasting based on data, which may be applicable and useful to government and business institutions.

Sudan GDP Annual Growth Rate Forecasts are projected using an autoregressive integrated moving average (ARIMA) to be 4.9 for 2017 and 4.9 for 2020, using analysis expectations. We model the past behavior of Sudan GDP Annual Growth Rate using historical data and adjustments of the coefficients of the econometric model by taking into account analysis assessments and future expectations. It can be seen that time series are very complex because each observation is somewhat dependent upon the previous observation, and often is influenced by more than one previous observation. Random error is also influential from one observation to another. These influences are called autocorrelation-dependent relationships between successive observations of the same va- 
riable. The challenge of time series analysis is to extract the autocorrelation elements of the data, either to understand the trend itself or to model the underlying mechanisms.

A word of caution about using multiple regression techniques with time series data: because of the autocorrelation nature of time series, time series violate the assumption of independence of errors. Type I error rates will increase substantially when autocorrelation is present. Also, inherent patterns in the data may dampen or enhance the effect of an intervention; in time series analysis, patterns are accounted for within the analysis.

\section{Conclusion}

This article has discussed the analysis for GDP statistics of the Sudan. The ARIMA method used here might be appropriate only for a time series that is stationery (i.e., its mean, variance, and autocorrelation should be approximately constant through time) and it is recommended that there are at least 50 observations in the input data (the underlying model has 55 observations). It is also assumed that the values of the estimated parameters are constant throughout the series. The article has discussed changes in the GDP for the period (1960-2015). The results for the analysis, indicated that model, provides useful information for identifying GDP trend. An important policy consideration rising from the study is that there is increasing trend for the model of the data. More advanced future work can be done on the basis of these investigations, particularly in residual analysis of the model.

\section{Conflicts of Interest}

The author declares no conflicts of interest regarding the publication of this paper.

\section{References}

[1] Box, G.E., et al. (1994) Time Series Analysis: Forecasting and Control. 3rd Edition, Prentice Hall, Englewood Cliffs, NJ.

[2] Brockwell, P.J. and Davis, R.A. (2002) Introduction to Time Series and Forecasting. 2nd Edition, Springer, New York. https://doi.org/10.1007/b97391

[3] Yang, L. (2009) Modeling and Forecasting China's GDP Data with Time Series Models. D-level Essay in Statistics. Department of Economics and Society, Hogskolan Dalarna, Falun.

[4] Andrei, E.A. (2011) Econometric Modeling of GDP Time Series. Theoretical and Applied Economics, 18, 91-98.

[5] Boshnakov, G.N. (2016) Introduction to Time Series Analysis and Forecasting, 2nd Edition, Wiley Series in Probability and Statistics, by Douglas C. Montgomery, Cheryl L. Jennings and Murat Kulahci (eds). Published by John Wiley and Sons, Hoboken, NJ, USA, 2015. Total Number of Pages: 672 Hardcover: ISBN: 978-1-118-74511-3, ebook: ISBN: 978-1-118-74515-1, etext: ISBN: 978-1-118-74495-6. Journal of Time Series Analysis, 37, 864. https://doi.org/10.1111/jtsa.12203

[6] Baum, C.F. (2007) Powerful New Tools for Time Series Analysis. Boston College \& 
DIW.

[7] Pasavento, E. (2007) Residuals-Based Tests for the Null of No-Co Integration: An Analytical Comparison. Journal of Time Series Analysis, 28, 111-137. https://doi.org/10.1111/j.1467-9892.2006.00501.x

[8] International Monetary Fund (IMF) (2014) World Economic Outlook (WEO) Database. Global Finance Magazine.

[9] Central Bank of Sudan (2015) Sudan GDP and Economic Data. Country Report 2015.

[10] (2015) Sudan GDP Annual Growth Rate.

http://www.tradingeconomics.com/sudan/gdp-growth-annual/forecast 